
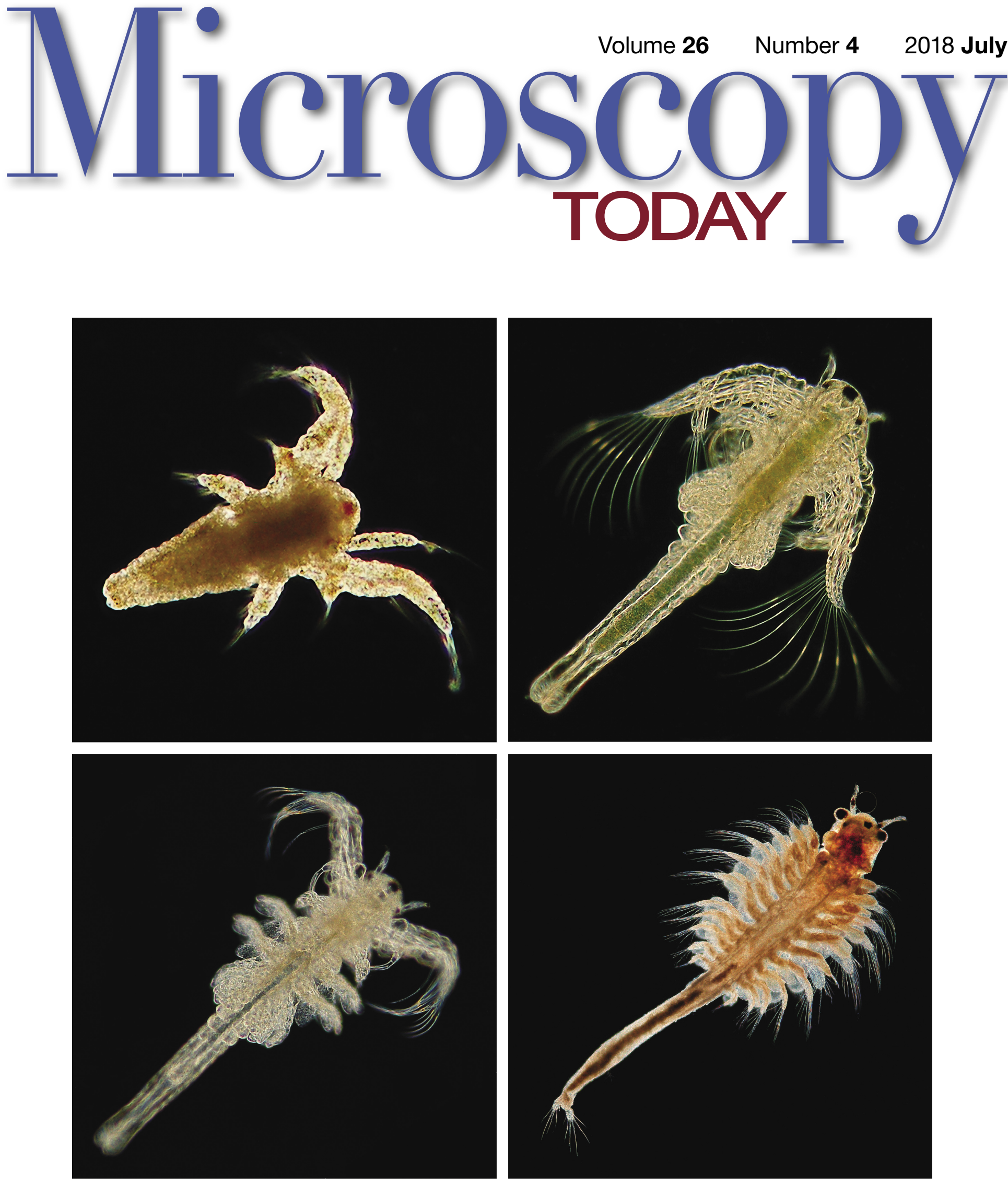


\section{$\in$ THOS}

Focused lon and Electron Beam System

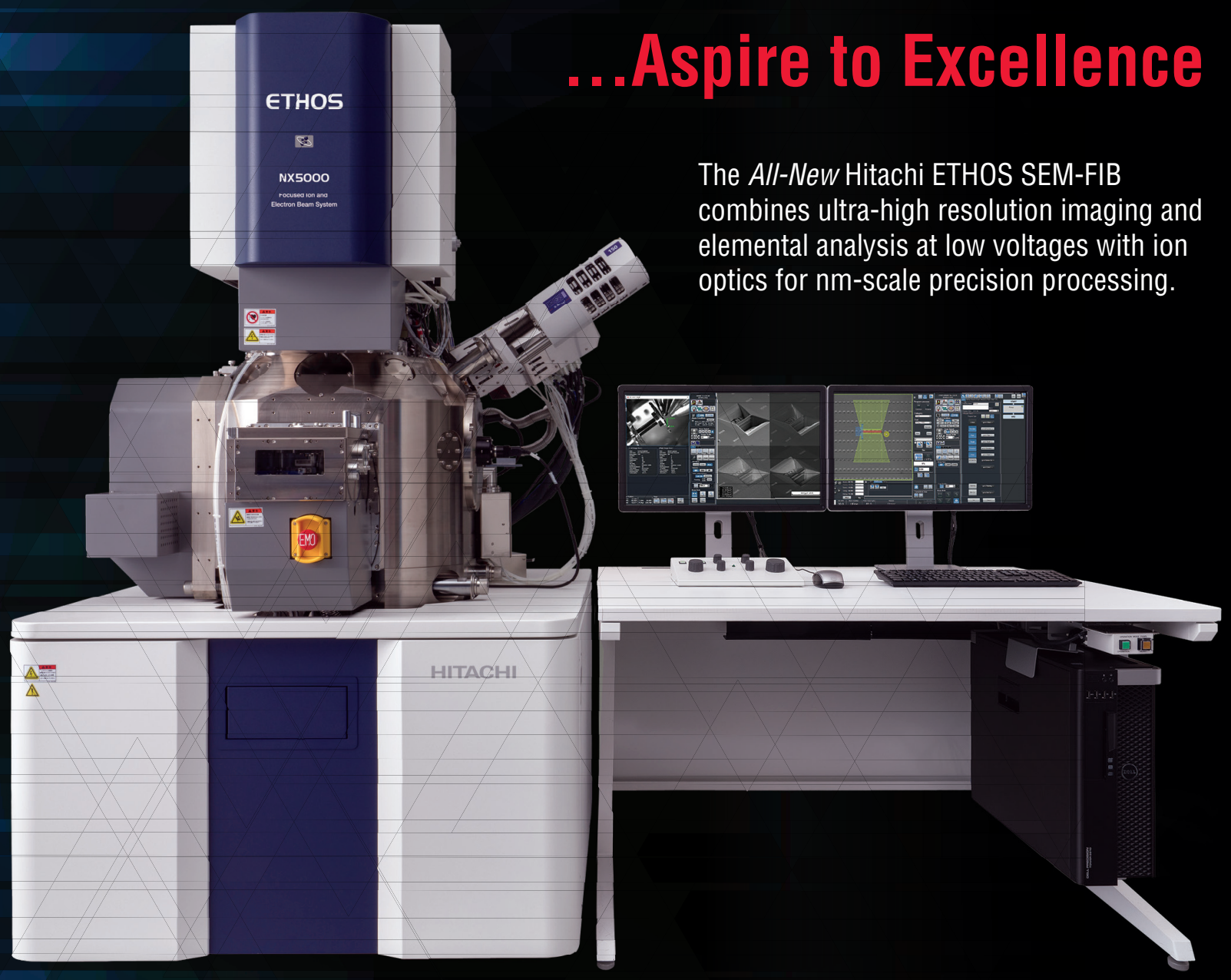

Designed with a variety of applications in mind

- $\quad$ Large analytical specimen chamber for numerous accessories

- Automated operation including macro processing

- Time sharing mode for dual simultaneous live imaging and processing

- $\quad$ Real-time analytical 3D segmentation capability

\section{Advanced Microsampling}

- Sample orientation control with Anti Curtaining Effect (ACE) technologies

- 4-axis lift-out function for advanced TEM specimen preparation

Triple-beam system yielding highest-quality results

- Low acceleration voltage processing with noble gas ion beam

- $\quad$ Selectable ion species (argon/xenon)

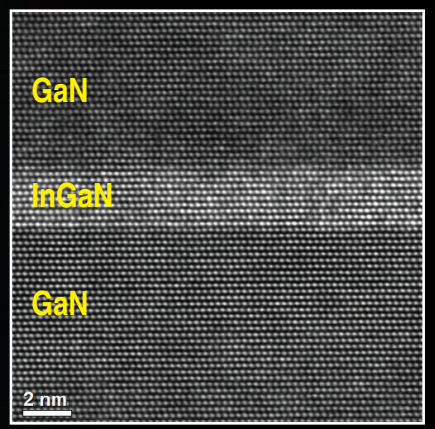

$200 \mathrm{kV}$ ADF STEM Image of processed lamella by Triple Beam Ar lon at 1kV

\section{rol unore information, visit www.hitachi-hightech.com/us/ifb}




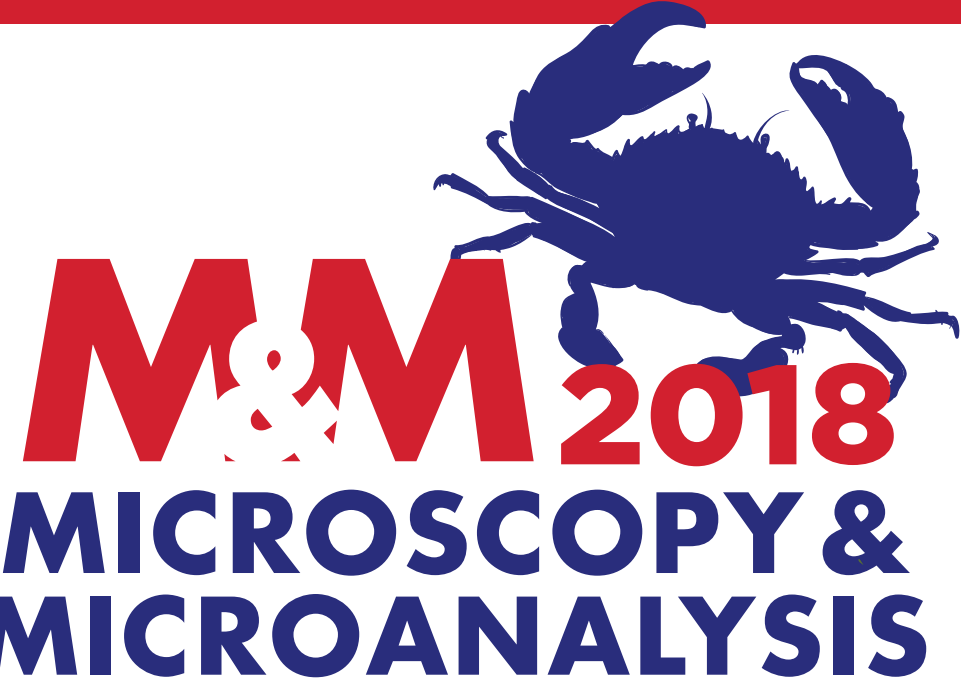

August 5-9, 2018 - Baltimore, MD

\section{www.microscopy.org/MandM/2018}

\section{0 poster presentations over 4 days}

$>120$ companies in the largest microscopy-related exhibit hall in the world

70 FREE Vendor Tutorials

35 named symposia in Physical, Biological, and Analytical Sciences

7 traditional day-long Sunday Short Courses

3 in-depth, pre-meeting Congresses on featured topics,

3 featuring platform and poster presentations and networking

2 fascinating Plenary Session speakers (on 50-cent microscopes, and finding micrometeorites on your roof!)

4 vibrant, historic, waterfront city (with 650 daily flights from 70 destinations) 


\section{thermoscientific}

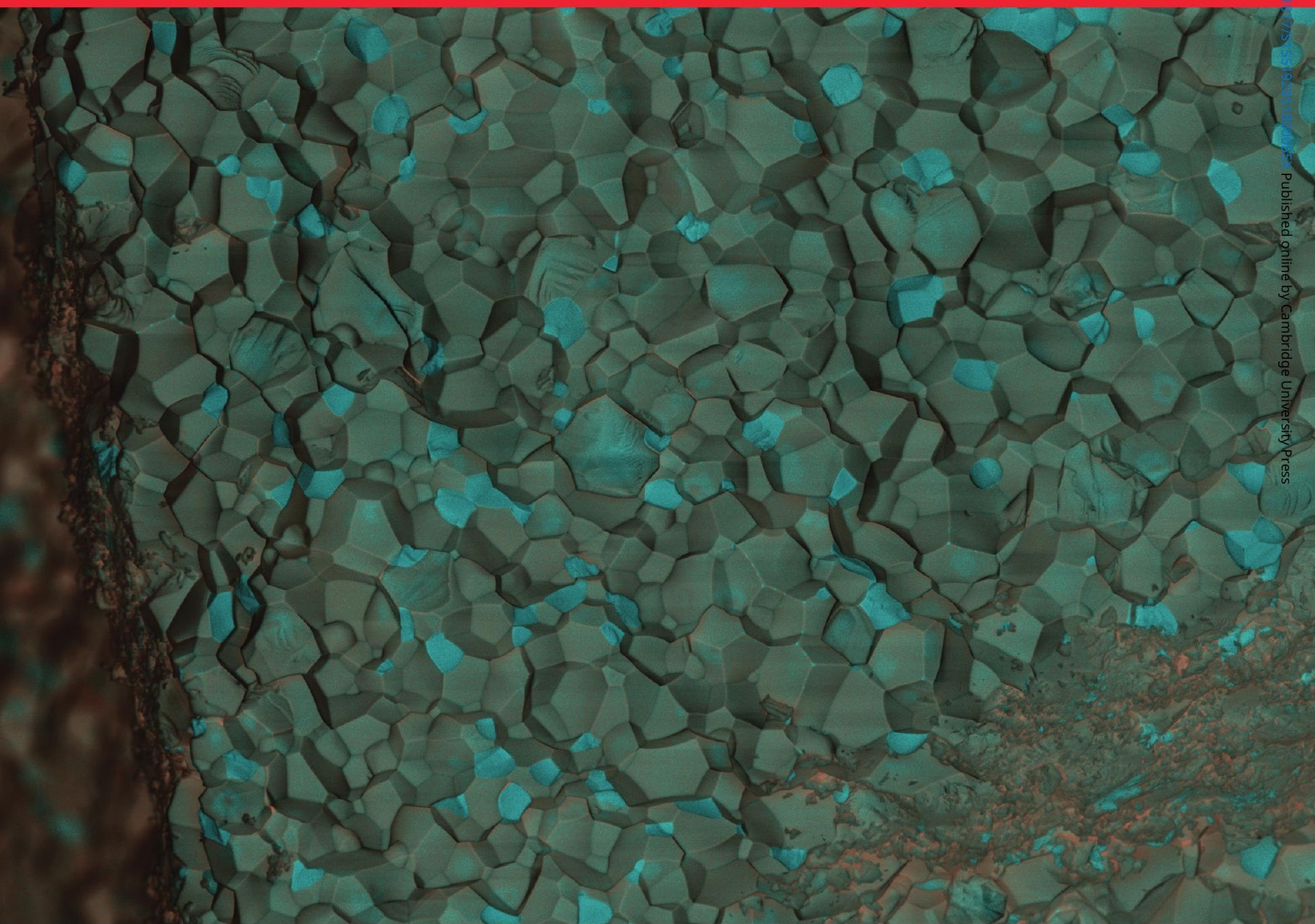

\section{Prisma E SEM for Materials Science}

The new Prisma E scanning electron microscope (SEM) combines a wide array of imaging and analytical modalities with new advanced automation to offer the most complete solution of any instrument in its class. It is ideal for industrial R\&D, quality control, and failure analysis applications that require high resolution, sample flexibility and an easy-to-use operator interface. Prisma E SEM succeeds the highly successful Quanta SEM.

Find out more at thermofisher.com/EM-Sales

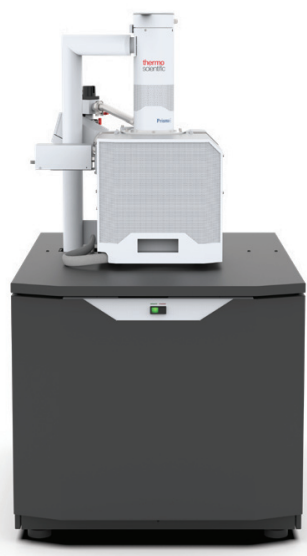

ThermoFisher S C I E N T I F I C 


\section{Contents}

About the Cover

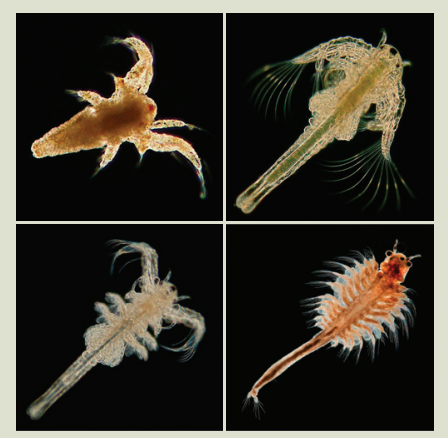

Morphological differentiation of Artemia franciscana during development from birth to full adult. Top: day 1 (left) and day 13 (right), bottom: day 22 (left) and day 35 (right). Various magnifications.

See article by Piper.

\section{Microscopy}

\section{Light Microscopy}

12 Artemia: A Model Specimen for Educational Microscopy Projects in Biological and Ecological Fields Jörg Piper

20 Guidelines for Understanding Magnification in the Modern Digital Microscope Era

James A. DeRose and Michael Doppler

\section{Electron Microscopy}

34 Stereoscopic Effects from Single SEM Images Robert Sturm

\section{Meeting Preview}

40 IMC19: 19th International Microscopy Congress in Australia Nicola Thomas

\section{Pioneers of Microscopy}

44 Cryosectioning and Immunolabeling: The Contributions of Kiyoteru Tokuyasu

Gareth Griffiths, Jan-Willem Slot, and Paul Webster

\section{Highlights from Microscopy and Microanalysis}

56 Assessing Soft-Tissue Shrinkage Estimates in Museum Specimens Imaged With Diffusible lodine-based Contrast-Enhanced Computed Tomography (diceCT)

56 Characterization of Lithium Ion Battery Materials with Valence Electron Energy Loss Spectroscopy

57 Electron source brightness and illumination semi-angle distribution measurement in a transmission electron microscope

\section{Departments}
7 Editorial
8 Carmichael's Concise Review
50 Industry News
52 Product News

60 NetNotes

68 Calendar of Meetings

72 Dear Abbe

74 Index of Advertisers 
Providing microscopy supplies and specimen preparation equipment to our valued customers for half a century.

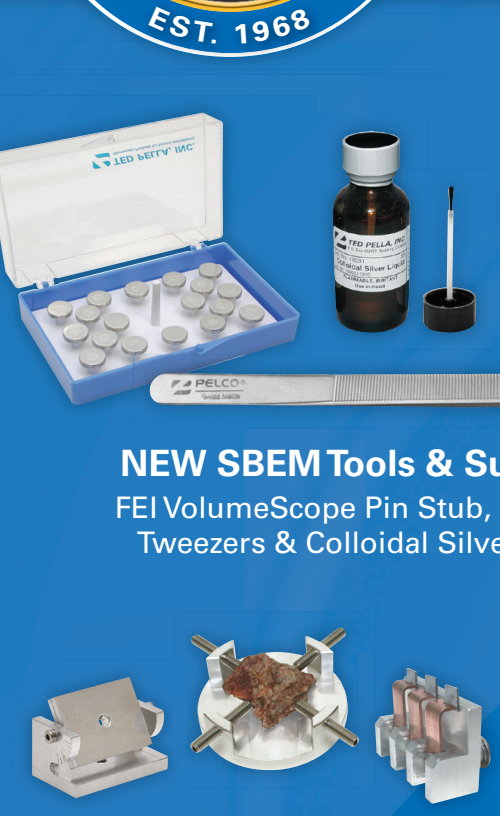

PELCO ${ }^{\circledR}$ Modular SEM

Holders \& Mounts

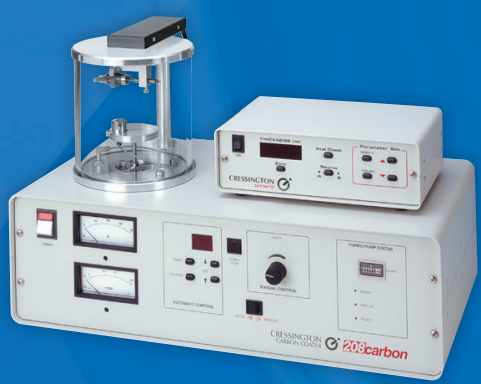

Cressington Coating Systems

Carbon Evaporation \& Metal Sputtering

\section{ies}

Visit us August 3-5 in Balitimore, MD

M\&M 2018 | B00TH\#1012

\section{(1)}
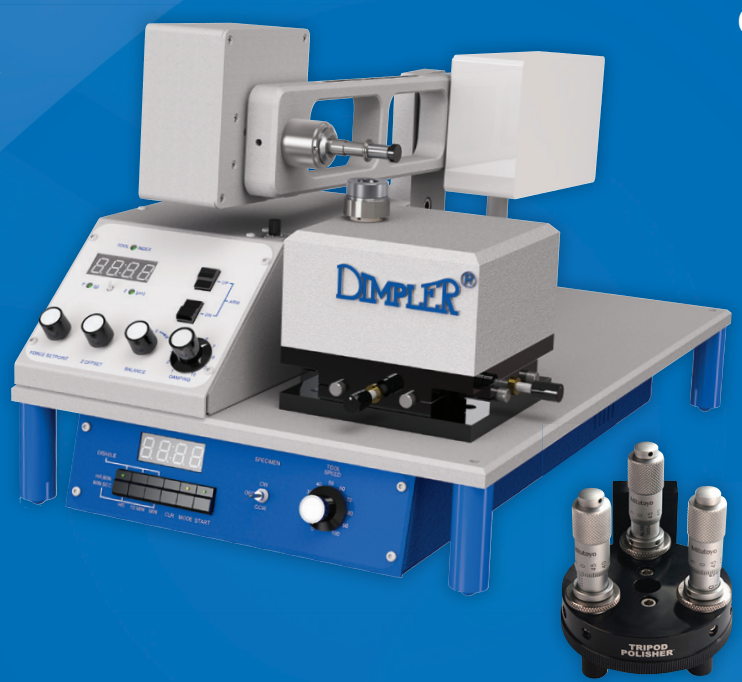

NEW Products for Specimen Thinning in Preparation for Electron Microscopy

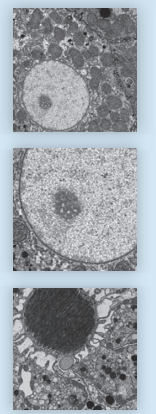

M\&M 2018 Vendor Tutorial

Join us Tuesday, August 7 at 5:45pm, Booth \#1012

\section{PELCO BioWave ${ }^{\circledR}$ Pro+ Assisted}

Serial Block-Face SEM (SBEM)

Using the PELCO BioWave ${ }^{\circledR}$ Prot, the entire SBEM process

can now be completed in under a day with identical

results to the standard long protocol.

Images: Rick Webb, University of Queensland

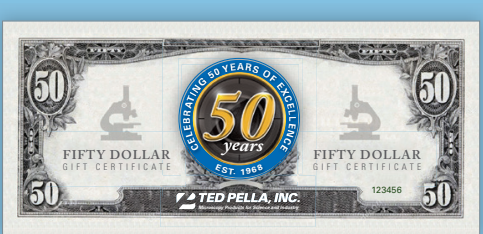

WIN \$5O OFF YOUR NEXT ORDER:

Visit us at M\&M 2018, and enter to win one of fifty gift certificates for $\$ 50$ off your next order.

\section{TED PELLA, INC. \\ Microscopy Products for Science and Industry}

www.tedpella.com sales@tedpella.com 800-237-3526 